\title{
PARA GOZAR A ESTA MUJER DIERA EL ALMA. EL MITO FÁUSTICO Y SUS RESCRITURAS EN LA LITERATURA ESPAÑOLA
}

\author{
ISABEL HERNÁNDEZ \\ Universidad Complutense de Madrid
}

\section{RESUMEN}

El presente artículo trata de indagar en la recepción del personaje de Fausto en las letras españolas a partir del libro popular alemán, así como de de la posterior versión teatral realizada por Goethe, haciendo un especial hincapié en las épocas en que este mito literario ha despertado una mayor atención e incidiendo en los motivos que pudieron provocar su recepción.

Palabras clave: Fausto, literatura alemana, literatura española, recepción.

\section{WOULD, TO POSSESS THIS WOMAN, GIVE MY SOUL. THE FAUSTIAN MYTH AND ITS REWRITING IN SPANISH LITERATURE}

\begin{abstract}
This article aims to explore the reception of the figure of Faust in Spanish literature based on the Volksbuch as well as on Goethe's later drama version, considering those moments in time, in particular, when this literary myth was the object of greater attention, and highlighting the possible reasons which could have produced its reception.
\end{abstract}

Key words: Faust, German literature, Spanish literature, reception.

Hay en la literatura española muchas más naturalezas fáusticas de lo que la crítica ha señalado hasta el momento. El hecho de que determinadas obras no hayan sido estudiadas desde esta perspectiva se debe seguramente a que el personaje de Fausto ha sido considerado desde siempre como el personaje prototípico del alma alemana, difícil de encajar, por tanto, en la hispana, más dada a generar vivaces Lázaros, Guzmanes, Estebanillos o Justinas que dubitativos Faustos. No obstante, ya Udo Rukser, en su conocido estudio Goethe in der hispanischen Welt (1958), supo ver con acierto que el Fausto era la obra que había «pasado a enriquecer el acervo intelectual del mundo hispano como ninguna otra obra de Goethe y, lo que es más, como ninguna otra obra de la 
literatura extranjera» ${ }^{1}$. Y es que, como también afirma Rukser, una vez tomado cuerpo en territorio español el proceso de secularización que trajo consigo el desarrollo de una sociedad burguesa culta e ilustrada, los lectores comenzaron a reconocerse a sí mismos en el personaje de Fausto y a entenderlo como prototipo del individuo moderno, de manera que la fascinación que la obra ejercía no dejaba de ir cada vez más en aumento. Así, a medida que el tardío Romanticismo español comenzó a cobrar cuerpo, fue precisamente el personaje de Fausto y no otro el que se convirtió en su símbolo ${ }^{2}$, puesto que ya los primeros románticos vieron en él al representante ideal de su fascinación por lo maravilloso, lo demoníaco y lo popular a un tiempo. Y fue precisamente a los románticos, a quienes este afán de buscar en Fausto la justificación de sus inquietudes llevó a poner de manifiesto por primera vez las relaciones entre el personaje de Fausto y la literatura española. Tal como recoge Udo Rukser en su mencionado estudio, el 25 de julio de 1870 el dramaturgo Adelardo López de Ayala pronunció una conferencia en la Real Academia Española en la que afirmaba que Goethe se había inspirado en El mágico prodigioso (1637) de Calderón para componer su drama. La resonancia de la idea fue tal que la propia academia decidió organizar, con ocasión del segundo centenario de la muerte de Calderón, un certamen basado en la siguiente pregunta: «¿Qué relaciones existen según la crítica literaria entre El mágico prodigioso de Calderón y el Fausto de Goethe, teniendo en cuenta las tradiciones y leyendas en las que los dos autores puedan eventualmente haberse inspirado?» ${ }^{3}$.

La lectura de ambas obras permite atestiguar fácilmente estas relaciones si se tiene en cuenta además que la leyenda del doctor Fausto contaba ya con cierta difusión en los ambientes cultos de la España del Siglo de Oro, tal como testimonia Conrad Gesner en una carta fechada el 15 de agosto de 1561 describiendo la fama extraordinaria de que gozaba este personaje entre los estudiantes de Salamanca, difundida probablemente a través de los denominados Volksbücher, los libros populares, y tal como se percibe también en las Disquisiciones mágicas de Martín del Río (1599), donde se narra una de las proe-

\footnotetext{
${ }^{1}$ Existe traducción española: RUKSER, Udo. Goethe en el mundo hispánico. México/ Madrid: FCE, 1977, 123.

${ }^{2}$ Cfr. RUKSER, Udo, Ibidem.

${ }^{3}$ Fue premiado el trabajo de Antonio Sánchez Moguel que se publicaría en 1881 con el título de «El mágico prodigioso y el Fausto de Goethe». El mismo Rukser explica que, como era de esperar, la respuesta de Moguel a la pregunta fue negativa, a pesar de que la descripción de Fausto y de sus anhelos resulta un tanto liviana: «El joven filósofo de Antioquía está lleno del deseo de buscar a Dios, en tanto que el viejo profesor alemán es un escéptico que no tiene más deseo que el de gozar de la vida: ¿qué tienen los dos en común? Si uno de ellos vende su alma al demonio para obtener nueva vida, y el otro para poseer la mujer amada, ¿hay en esto coincidencia alguna, excepto en cuanto a la forma del pacto?... El demonio de Calderón es el Satanás cristiano, el eterno enemigo del hombre, en tanto que Mefistófeles es la personificación más lograda de un escepticismo inverosímil.» Citado según Rukser, 1977: 129.
} 
zas o experiencias mágicas de Fausto. También es posible que los dramaturgos españoles conocieran la versión dramática del Fausto (1604) de Christopher Marlowe y, consciente o inconscientemente, se dejasen influir por el modelo, adaptándolo a una época y a una mentalidad distintas. Por consiguiente, parece lógico que autores como Mira de Amescua, Lope de Vega o Calderón ${ }^{4}$ conocieran, de forma directa o indirecta, la trágica historia del nigromante alemán, además de los textos de la tradición hispana en los que ya se recogían pactos con el diablo ${ }^{5}$. No obstante, las diferencias que se aprecian entre la concepción de la trama fáustica y los textos españoles en los que se rescribe son más que llamativas, sobre todo por el hecho de que la condición de los personajes y la finalidad perseguida por ellos en ambos casos son, por lo general, bien diferentes. Y es que en estos últimos se descubre una tendencia clara a rescribir la biografía del protagonista partiendo de leyendas hagiográficas preexistentes, al tiempo que el personaje establece un pacto con el diablo y se introduce en las artes mágicas con la única finalidad de conseguir a la mujer que desea y no el conocimiento absoluto ${ }^{6}$. Es, por tanto, el amor el que tarde o temprano se apodera de todos estos personajes; pero los amores que persiguen van en contra de los cánones estipulados por la sociedad y, de entrada, están condenados a la marginalidad, por lo que, en una reformulación de carácter religioso de lo que serían enredos de tipo celestinesco, no piensan en ningún momento en recurrir a una alcahueta, sino al propio demonio,

${ }^{4}$ Según recoge Pedro Ballesteros Barahona en su tesis doctoral Calderons erste Fassung von 'El mágico prodigioso' und das Doctor-Faustus-Spiel der englischen Komödianten (63) parece ser que Calderón conoció la obra de Marlowe a partir de la versión de algún grupo de comediantes ingleses, cuya representación pudo ver cuando se encontraba en Flandes como soldado de los ejércitos españoles. Juan Vera Tasis y Villarroel, el amigo y editor de su obra, asegura que entre 1625 y 1635 Calderón estuvo primero en Milán y luego en el sur de los Países Bajos, aunque otros biógrafos fechan esta estancia entre 1623 y 1625.

${ }^{5}$ En este sentido no debe pasarse por alto el exemplo XLV titulado «De lo que contesçió a un omne que se fizo amigo et vasallo del diablo» recogido en El conde Lucanor de Don Juan Manuel. Aquí, no obstante, la finalidad del pacto es otra bien distinta, pero se sella en las mismas condiciones, pues el ejemplo desarrolla la historia del hombre rico que súbitamente se ve abocado a la pobreza y recurre al diablo para recuperar su condición: «Quando el omne oyó decir que era el Diablo, tomó ende muy grand reçelo, pero por la grand cuyta et grand mengua en que estava, dixo al Diablo que si él le diesse manera commo pudiesse seer rico, que faría cuanto él quisiesse». (235). También las estrofas 1454-1474 del Libro de Buen Amor del Arcipreste de Hita incluyen el ejemplo de las andanzas de un ladrón que rinde vasallaje al diablo: «[...] díxol que de su alma la carta le feçiese / e furtase sin miedo quanto furtar pudiese. / Otorgó le su alma, fizo dende carta; / prometió le el diablo que dél nunca se parta».

${ }^{6}$ El afán de trascender la realidad por medio del conocimiento fue uno de los componentes definitorios del espíritu del renacimiento europeo, que vio nacer precisamente una de las versiones más conocidas de la leyenda de Fausto, la de Christopher Marlowe. A pesar de ello, la trasgresión que lleva consigo esa sed desmedida de conocimiento no justifica aquí tampoco la renuncia a la fe cristiana en nombre del vasallaje diabólico al que se somete el individuo tras efectuar el pacto. 
prometiendo, en lugar de riquezas materiales, ni más ni menos que el alma, tal como se lee en los versos de similar calado de Mira,

Por gozar de ti, Leonor daré el alma. (vv. 1426-1427)

Moreto,

Y por gozar de Leonor diera el alma. (591a)

y Calderón:

Para gozar a esta mujer

diera el alma. (vv. 1198-1199)

De este modo, llevado por el deseo de poseer un poder sobrenatural con el que ejercer cierto dominio sobre todo lo mundano, el hombre establecería una alianza, un pacto con el demonio, por el que se contraerían, teóricamente, obligaciones por ambas partes. Este pacto, lejos de presentar una forma homogénea y unitaria, presenta múltiples formas en función de cada texto, dependiendo la mayoría de las veces de la finalidad que se persigue con la intervención del diablo ${ }^{7}$. No obstante, en todos los casos, la tentación del maligno en su primer acercamiento al personaje se proyecta hacia el ánimo débil del protagonista, fomentando en él un sentimiento de plena confianza y una intensa fascinación que constituirán las bases emocionales de su determinación al pacto. El diablo es consciente de que el hombre sólo lo sellará si no le importa su propia caída; de ahí que se empeñe siempre en exigir una manifestación explícita de este consentimiento. De este modo, las artimañas del maligno para obtener lo firmado en el pacto y su imposibilidad de imponerse a la voluntad de Dios constituyen el eje fundamental en torno al que gira la acción.

Con todo, no puede ponerse en duda que existen claras relaciones entre la trama fáustica y los textos españoles; pero, aun siendo esto así, esta afirmación podría hacerse extensiva a muchas otras obras españolas de carácter religioso, publicadas más o menos por los mismos años, en las que los protagonistas tienden a pasar con mucha facilidad de la incredulidad al escepticismo filosófico característico del Fausto alemán. Así ocurre, por ejemplo, en dos piezas de gran resonancia en la época: El condenado por desconfiado de Tir-

\footnotetext{
${ }^{7}$ Según Natalia Fernández «el summum de la ironía diabólica, si es que puede denominarse así, se da en los casos de pacto con sangre. La evidente espectacularidad que proporciona este motivo redunda en una profunda riqueza de contenido: la sangre, germen de vida, fecundidad y futuro, símbolo de la pasión de Cristo y, por consiguiente, de la redención, se degrada irónicamente a sellar la unión con Satán, la muerte y la nada, el sacrificio inútil del hombre vencido y la temible condenación eterna». FERNÁNDEZ RODRÍGUEZ, Natalia (25).
} 
so de Molina y El esclavo del demonio (1612) de Mira de Amescua ${ }^{8}$. Para la composición de su obra, Mira se inspiró en una leyenda hagiográfica medieval: la del monje portugués fray Gil de Santarém, la cual, fusionada con la función casi «celestinesca» que desempeñaba el diablo en los textos en los que se describían pactos con él, se avenía muy bien con el horizonte de expectativas del público español de la época. A su vez el mito de este santo que pacta con el diablo a cambio de un poder claramente terrenal tenía ya antecedentes que pueden rastrearse en los Milagros de Nuestra Señora de Gonzalo de Berceo ( «De cómo Teófilo fizo su carta con el diablo de su ánima et después fue convertido e salvo» $)^{9}$, que, a su vez, procede de una versión latina de las muchas que circularon acerca de Teófilo de Adana, mayordomo de un obispado de Silicia, muerto hacia 538, recogida en griego y traducida al latín en el siglo VIII por Pablo Diácono. Teófilo es un hombre que pacta con el diablo para asegurar su bienestar en este mundo, amenazado por la aparición de un nuevo vicario que lo hace descender en la consideración general y generar un sentimiento de envidia cada vez más pronunciado. Pero Teófilo no invoca directamente al demonio, sino que se escuda en la ayuda de un nigromante judío, aunque de igual manera se verá inmerso en el mismo proceso que todos aquellos que contraen el pacto y no le quedará más remedio que renunciar a su fe:

${ }^{8}$ En su estudio «El santo, el diablo y la «sutil nigromancia» (Notas sobre el Fausto español del Siglo de Oro)»(83-95), Aldo Ruffinatto menciona también la Gran columna fogosa de Lope de Vega, inspirada en la leyenda de San Basilio, donde aparece el pacto asociado al amor: el joven criado Patricio se enamora perdidamente de su señora, Antonia, decidida a consagrar su vida a Dios. Desesperado ante la evidente imposibilidad de cumplir sus deseos, recurre a un encantador que, a la vista de su absoluta osadía, le pone en contacto con el mismo Satán. Una vez ante él, firmará una cédula por la que se compromete a entregarle su alma a cambio de que la dama caiga rendida a sus pies. Efectivamente, por intervención del maligno, Patricio llegará a casarse con Antonia, pero con el tiempo la esposa sospecha del vasallaje de su marido al diablo, por lo que recurre a Basilio, famoso por su magnanimidad. Tras una dolorosa penitencia, el santo consigue recuperar la cédula y Patricio consigue el perdón. El esclavo del demonio se publicó en 1612 en la Tercera parte de las comedias de Lope de Vega y otros autores, con sus loas, y entremeses. En 1657 Agustín Moreto, Jerónimo de Cáncer y Velasco y Matos Fragoso publicaron conjuntamente la pieza titulada Caer para levantar inspirada claramente en la de Mira.

${ }^{9}$ Es el milagro XXIV. Aparte de esta versión deben tenerse en cuenta también la de la Cantiga CCXVI de Alfonso X el Sabio, del siglo XIII, y la que aparece en el Libro de los Enxiemplos por $a, b, c$ del siglo XV, obra atribuida a Clemente Sánchez de Vercial. Lo que aquí se relata es una buena muestra de cómo la propia religión católica estaba plagada de elementos sobrenaturales que, a través de la predicación y los sermones, se transmitían paulatinamente a la conciencia popular. El más importante, por lo que a la evolución de la trama fáustica se refiere, es la creencia en el demonio, la fe en su presencia real, que estaba en la base de la enseñanza eclesiástica, y que, desde ahí, invadió toda la literatura hagiográfica. 
705 Era un omne bono de granada fazienda avié nomne Teófilo, como diz la leyenda; omne era pacífico, non amava contienda, bien sabié a sus carnes tenerlas so su rienda. [...]

719 En casa del obispo non era tan privado como solié seer con el otro passado; fo en so voluntat fierament conturbado, aviélo la envidia de su siesto sacado.

720 Teniésse por maltrecho e por ocasionado, de grandes e de chicos vediése desdeñado; cegó con grand despecho e fo mal trastornado, asmó fiera locura, yerro grand, desguisado. $[\ldots]$

739 Díssoli el diablo: «Non serié buen derecho a vasallo ageno yo buscar tal provecho; mas deniegue a Cristo, que nos faz muy despecho, facerli é que torne en todo so bienfecho.

740 Deniegue al so Cristo e a Sancta María, Fágame carta firme a mi placentería, Ponga ý su seyello a la postremería; Tornará en su grado con muy grand mejoría».

En el siglo X, Roswitha von Gandersheim dio categoría de leyenda a esta $\operatorname{trama}^{10}$ y Rutebeuf, en el XIII, le añadió por primera vez el motivo del pacto con sangre (Le miracle de Téophile). A través de textos como éstos, así como de las predicaciones y los ejemplos, la figura del diablo se popularizó y su presencia en la vida cotidiana se convirtió en algo asumido y casi familiar para los hombres de la época, hasta el extremo de que el folclore llegó incluso a denigrarlo, de tal modo que «su ridiculez e impotencia contrastaban con la malignidad originaria, bíblica, latente, pero es precisamente esta paradoja la que le confería su innegable efectismo a ojos de un público cuyo aprendizaje moral no procedía de profundas conceptualizaciones filosófico-teológicas, sino de ejemplos concretos, tomados de la vida de quienes eran capaces de vencer a la bestia amparados en la gracia de Dios» ${ }^{11}$. De este modo, la hagiografía

\footnotetext{
${ }^{10}$ «[...] Si quiere ser mi seguidor deberá negar, y por escrito, / A Cristo y a la virginal madre de Cristo, / Que con el nacimiento de su hijo me ha causado un daño inmenso. / A quien se convierta en mío elevaré, pues puedo hacerlo. / Le proporcionaré una posición tan esplendorosa a la vista de todos, / Que incluso el obispo no se atreverá ya / A oponerse a sus órdenes, y más, cuando vea que todos / Honran a aquél, a quien hoy aún desprecian.» / A estas palabras, expresadas con astucia por la serpiente, / No repuso ni una sola palabra el desgraciado, / Anhelante de que el dragón cumpliera lo que había prometido. / De este modo se entregó el renegado totalmente a la perdición, / Voluntariamente sellando con el pacto su propia desgracia». Roswitha von Gandersheim, Teófilo. En: PARRA MEMBRIVES, Eva. Roswitha von Gandersheim (68-69).

${ }^{11}$ FERNÁNDEZ RODRÍGUEZ, Natalia (15).
} 
portuguesa unió esta leyenda a la del histórico Fray Gil, muerto en 1256, quien, mediante un pacto con el diablo, había aprendido magia negra en Toledo para, al igual que Teófilo, acabar salvando su alma por intercesión de la Virgen.

Don Gil, un hombre sabio y religioso, es tentado por una ocasión que se le presenta de gozar de los amores de Lisarda y la aprovecha, emprendiendo a partir de ese momento un camino sin retorno que lo llevará a pactar con el diablo. Lisarda se encuentra en la misma situación, pues ha transgredido la autoridad de su padre negándose a contraer matrimonio con el pretendiente que éste le tiene destinado. Y así, metiéndose en el cuerpo de un criado dormido el diablo favorece la unión de Gil con Lisarda, a la que poco antes el protagonista había defendido de los ataques de su galán, para caer luego él mismo en una vida de pecado, convencido de que no puede hacer nada para oponerse a la fuerza del destino, tal como le dice el diablo:



Tras ello los dos se sitúan al margen de los valores establecidos en la época y se arrojan al camino de la perdición en una impetuosa fuga que los lleva a convertirse en bandoleros y a vivir y a actuar ajenos a la moral vigente y pertrechando toda suerte de actos delictivos. Son personajes que encarnan, pues, todas las maldades que se le pueden atribuir al maligno y son por ello «esclavos del demonio» que no atienden más que a su faceta carnal y se entregan a las bajas pasiones. La aparición del diablo, de nombre Angelio, trastorna completamente a Gil, que le vende su alma a cambio de aprender nigromancia para gozar de Leonor, la hermana de Lisarda, de quien se acaba de enamorar:

\author{
Si aprendo la sutil nigromancía \\ que el católico llama barbarismo, \\ y excediendo las fuerzas de mí mismo \\ gozare de Leonor un breve día, [...] (vv. 1552-1555)
}

Al enterarse de ello, Lisarda busca refugio en Dios, aunque para purgar sus pecados ha de verse humillada a la condición de esclava. El deseado encuentro de Gil con Leonor hace que se descubra el engaño, pues ella desaparece ante su vista cuando pretendía haberla conseguido, hecho que constituye el punto de partida para el desengaño del protagonista, que con ello se da cuenta de su error. Tras un sinfín de horrendas peripecias acaba viendo la verdad y volviendo a su verdadero ser de hombre religioso, sabio y virtuoso por intercesión del ángel de la guarda, que vence en combate al demonio y 
reintegra al fraile la cédula del pacto ${ }^{12}$. He aquí, pues, la gran diferencia, patente ya en la leyenda de Teófilo, entre los textos españoles y el Fausto alemán: si en el caso de este último la sed de conocimiento se va incrementando de manera proporcional a sus logros, lo que le lleva a hacer que todo posible arrepentimiento quede anulado ante la visión de los deleites mundanos, el de los personajes hispanos es sincero porque en él interviene directa o indirectamente la mano de Dios.

Otra característica significativa es la diferente concepción del personaje del diablo, mencionada ya anteriormente. Pues el diablo de Mira, que para no ensuciarse las manos confía a sus ayudantes la redacción y firma del pacto diabólico, tiene todos los elementos propios de la figura del fanfarrón poco de fiar que aparece en un buen número de las comedias de enredo del Siglo de Oro $^{13}$.

Teniendo en cuenta estos aspectos puede entreverse toda una serie de afinidades y, sobre todo, de preocupaciones comunes entre la obra de Mira y la de Calderón, considerada esta última durante algún tiempo entre las fuentes no endógenas del Fausto de Goethe. Tomando como punto de partida la vida de los santos Cipriano y Justina ${ }^{14}$ Calderón desarrolla la trama de la siguiente manera: en los primeros momentos en que empiezan a surgir comunidades cristianas en Roma, Cipriano, proclive al estudio, descubre un pasaje de la Historia natural de Plinio (II, V) que encierra una definición del Dios único. Desde hace ya tiempo está enamorado de Justina, una cristiana que rechaza a todos sus pretendientes, pues ha prometido dedicar su vida a Dios. Es, al igual que Fausto, un sabio que quiere conocer los secretos del mundo, pero aunque la primera escena de la obra presenta con claridad el contraste entre la soledad del estudioso en el campo y el bullicio de la ciudad en fiestas, Fausto y El mágico prodigioso sólo tienen en común el planteamiento de la situación, pues los finales son opuestos. Fausto es un erudito escéptico, inducido a la tentación por el diablo; es un soñador metafísico al que le importa más la adquisición de conocimiento que conseguir un amor inalcanzable. Sin embargo, Cipriano firma con su sangre el pacto propuesto por el demonio ignorando en buena medida la condición del mismo, para conquis-

${ }^{12}$ El hecho de que se sustituya en este punto la mediación de la Virgen, habitual en las leyendas tradicionales, por la del ángel de la guarda, puede deberse al propósito de enfatizar que este ángel es una metáfora del libre albedrío del hombre, que es quien realmente acaba venciendo al mal.

${ }^{13}$ En la Gran columna fogosa de Lope de Vega, cuya acción se desarrolla en el s. XIV y en la que el protagonista, Patricio, desea alcanzar asimismo los favores de una dama, Antonia, el diablo recupera parte de su calidad de tal: para llegar a él se necesitan intermediarios y exige en todo momento una claridad meridiana en los términos del contrato, pues sabe, por antigua experiencia, que no puede confiar en los hombres.

${ }^{14}$ La historia de Cipriano de Antioquía (siglo III) se recoge en múltiples versiones, pero no es hasta principios del siglo XVII cuando se asocia con el episodio del pacto demoníaco por influencia de testimonios dramáticos contemporáneos. 
tar el corazón de Justina. El demonio aparece primero como un galán y con las aptitudes de un maestro en teología, pero, tras fracasar en sus intentos de confundir a Cipriano por vía filosófica y teológica, hará todo lo posible para corromperlo por medio del recurso amoroso, es decir, por la misma vía que el de Mira, encendiendo en su corazón una pasión incontenible hacia esta hermosa dama que ya se había prometido de antemano a Dios ${ }^{15}$. Después, el diablo se le muestra a Cipriano como un gran maestro en las artes mágicas, lo que hace que el protagonista lo invite a su casa dándole el trato reservado a los huéspedes de honor. Lo que le muestra a Cipriano suscita en éste el asombro y el deseo de emulación y, por tanto, no duda en firmar con su sangre el pacto, al objeto de que el diablo le enseñe adecuadamente la magia necesaria para conseguir a la amada. De este pacto se deriva el hecho de que el diablo adopte definitivamente un papel de características celestinescas. Convertido en «mágico» (mago), tras un año de estudio con el diablo, Cipriano conjura a Justina, mientras el maligno intenta que ésta vaya al encuentro del protagonista sin conseguirlo, puesto que la ampara una fuerza superior a todas: la de Dios. Y por ello, en lugar de enviar a Justina en persona, el diablo se tiene que contentar con invocar un fantasma con la apariencia de Justina, que es el que acude en realidad al encuentro amoroso. Cuando Cipriano la tiene en sus brazos, la figura de Justina resulta ser tan sólo un esqueleto que se desvanece: es en ese momento cuando el estudioso comprende la verdad de lo leído en Plinio al comienzo de la obra, de manera que, gracias al benéfico influjo de la firmeza cristiana de Justina, acaba convirtiéndose a la nueva fe que determinará la posterior muerte de ambos como mártires.

Aquí, por tanto, el demonio vuelve a fracasar estrepitosamente y Cipriano, por el contrario, halla la salvación. Así se demuestra con rotundidad que «el mágico prodigioso» no es otro que Dios, que tiene poder omnímodo y, en consecuencia, supera al diablo: en el momento en que éste pretende usar su magia para atraer a Justina al amor apasionado por Cipriano, ésta duda y se resiste, y su firmeza vence al diabólico influjo por el hecho de estar amparada por el Dios único de los cristianos. De este modo, Dios es el gran protagonista de la trama, el actor principal, que contempla y determina los actos de todo lo que su creación mueve, incluyendo al diablo. Tampoco en este caso es una crisis de escepticismo lo que motiva el pacto, sino que Cipriano obedece a un móvil concreto: conquistar a Justina, a quien ama apasionadamente. Pero la virtud de la heroína triunfa y el demonio se ve obligado a confesar su impotencia ${ }^{16}$.

${ }^{15}$ Las concomitancias con la figura de Don Juan son aquí más que llamativas, puesto que, posteriormente, volverá a adoptar actitudes propias de este personaje al hacerse descubrir por uno de los dos galanes en la habitación de Justina.

${ }^{16}$ Otra obra de Calderón trata también el mismo tema, pero con un protagonista femenino: Las cadenas del demonio (1630). Irene lleva desde su nacimiento encerrada en una torre por su propio padre, Polemón, el rey de la Armenia inferior, para tratar de evitar que se 
A pesar de los elementos concomitantes que es posible encontrar entre Fausto y los protagonistas de Mira y Calderón es en una obra poco conocida de Juan Ruiz de Alarcón, Quien mal anda en mal acaba (1600-1609), donde se aprecia un mayor acercamiento a la trama fáustica: la obra se sitúa ya en España y en el tiempo presente, dejando atrás los escenarios históricos en los que se encuadraban las leyendas. El personaje principal es aquí un morisco malhechor, lo que da al diablo la posibilidad de actuar sin necesidad de ocultarse, casi como amigo, puesto que ya con anterioridad había prestado servicios a los abuelos del protagonista. En esta obra, sin embargo, cuando el protagonista está a punto de conseguir hacer realidad sus deseos amorosos gracias a los esfuerzos de ambos, aparece inesperadamente la Santa Inquisición, que obliga al diablo a desaparecer y descubre la identidad real del morisco. Todo acaba con la confesión de éste, con lo que se desvelan los engaños y se restablece el equilibrio inicial, que él mismo había quebrantado, algo, por otro lado, muy típico de la comedia barroca. Típico es también el hecho de que el diablo aparezca aquí, como en la práctica totalidad de las obras de la época, ridiculizado, aunque sin perder por ello su maldad inherente, su papel como tentador, haciendo gala de su eterno deseo de acarrear al hombre la perdición, presentando ante sus ojos todo aquello que pueda resultarle atractivo con la intención única de doblegar su voluntad y lograr que olvide la fidelidad debida a Dios.

Pero al margen de este buen número de obras hagiográficas escritas durante el Siglo de Oro, de las que sólo se han mencionado las más significati$\operatorname{vas}^{17}$, hay otro momento en la literatura española en que la trama fáustica cobra de nuevo un vivo interés: el siglo XIX. Como ya se ha apuntado al principio, el tardío romanticismo español supo ver rápidamente las posibilidades que ofrecía una trama como la de Fausto, no sólo por el pensamiento filosóficohumanista que encierra, sino también por lo referente a la presencia del demonio como personaje literario. De ahí que no resulte extraño que un autor

cumpla una profecía que la hacía responsable de la destrucción del reino por favorecer la propagación de una nueva fe. Su desesperación es tal que pacta con el demonio a cambio de su libertad, pero al final, el maligno es derrotado gracias a la predicación de san Bartolomé, quien, finalmente, hará que Irene abrace la nueva fe y, tras un exorcismo, se libere de las garras de Satanás.

${ }^{17}$ No puede pasarse por alto mencionar aquí un texto poco conocido, publicado el mismo año que El mágico prodigioso de Calderón, y en el que su autora recurre también al pacto diabólico como motivo central de la narración. Se trata «El jardín engañoso», décima novela de las que componen la colección de las Novelas amorosas y ejemplares (1637) de María de Zayas y Sotomayor. En un texto de marcada finalidad didáctica, el pacto con el diablo se realiza aquí también con el objetivo de conseguir a la dama deseada:

«- Pon tú el precio a lo que por mí quieres hacer, que aquí estoy presto a otorgarlo.

— Pues mándame el alma — dijo el demonio — y hazme una cédula firmada de tu mano de que será mía cuando se aparte del cuerpo, y vuélvete seguro que antes que amanezca podrás cumplir a tu dama su imposible deseo» (528). 
de la talla de José de Espronceda (1810-1842), gran admirador de la obra de Byron, encontrara en la historia del erudito alemán el argumento que buscaba para su gran epopeya inacabada: El diablo mundo (1841). Espronceda había conocido durante su estancia en París la versión francesa del Fausto que Gerard de Nerval publicara en 1828. Es sabido, además, que conocía la obra de Goethe, pues en una de las conferencias sobre literatura moderna que dictó en 1839 en el Liceo de Madrid, habló de él y lo definió como «el completador de la lengua y poesía moderna alemana, y como el primero que ascendió el yugo de la literatura francesa ${ }^{18}$. Pero la influencia que la obra de Goethe hubiera podido tener en este autor fue, si cabe, menor que la de Lord Byron. No obstante, la estructura de la composición revela elementos propios del Fausto de Goethe: en el primer canto aparece ya configurado el personaje del erudito anciano que, cansado del saber, se entrega a sus visiones y acaba rejuveneciéndose; las escenas que se desarrollan en una taberna recuerdan, cómo no, a la de la taberna de Auerbach, y tampoco falta en la obra un paralelo de la visita de Fausto a la habitación de Margarita. Además, la introducción es un gran panóptico en el que hay detalles que aparecen también en la descripción de la noche de Walpurgis. Todas estas similitudes han llevado a los críticos a plantearse una y otra vez la cuestión acerca de la originalidad de $E l$ diablo mundo y a buscar la fuente de inspiración del poeta en Byron o en Goethe, o en ambos autores a la vez ${ }^{19}$. Lo cierto es que en el poema se combinan las influencias de ambos; sin embargo, un análisis más detallado del texto permite afirmar que Espronceda lo concibió como una obra destinada a ser una versión española del Fausto de Goethe y del Manfred de Byron conjuntamente, «combinando en una síntesis original los aspectos visionarios de la primera con el titanismo y el humorismo sarcástico de la segunda, y pasando progresivamente del mundo de las ideas puras al de la realidad, incluso de la más sórdida ${ }^{20}$, algo que se aviene perfectamente con el gran ideal romántico que pretendía unificar lo normal y lo cotidiano con lo excepcional

${ }^{18}$ Según lo refiere Enrique Gil en su reseña de la conferencia publicada en El correo nacional el 12 de abril de 1839. Citado aquí según Robert Marrast en la introducción a su edición de El estudiante de Salamanca (25).

${ }^{19}$ Así el propio Antonio Ros de Olano en el prólogo que escribió para la publicación de la obra: «Repetimos que en nuestro juicio es el plan mayor que hasta hoy se ha concebido para un poema. Su héroe ha rejuvenecido ya como el doctor Fausto, pero su mocedad no es el préstamo de un tiempo mezquino, por la hipoteca y la enajenación del alma: el protagonista del Diablo Mundo, sin nombre hasta ahora, ha aceptado la juventud y la inmortalidad sin condiciones.

En el drama de Goethe, Fausto no es más que un mancebo a medias, porque su corazón es siempre el del doctor, y esto le hace no participar nunca de los placeres en sazón, antes por el contrario están siempre empozoñados por el juicio.

Acaso fue éste el pensamiento de Goethe, y nosotros nos guardaremos de tildarlo, porque esa continuada carcoma de Fausto es una sublimidad del talento que lo creó.» (167).

${ }^{20}$ MARRAST, Robert (58). 
y lo extraordinario. Esta dualidad será la característica que domine la composición de todo el poema, algo que se define ya desde el propio título, en el que se enuncia de manera explícita la permanencia del mal entre los humanos.

También el otro gran poema de Espronceda, El estudiante de Salamanca, presenta determinados elementos fáusticos, que algunos años después recogería Juan Valera en su espléndida novela Las ilusiones del doctor Faustino: el protagonista no tarda en perder sus ilusiones, porque no encuentra nada que pueda colmar sus anhelos infinitos. Por otro lado, la aparición de una mujer misteriosa y enigmática de la que se enamora perdidamente el protagonista, motivo que también se repite en su novela histórica Sancho Saldaña $(1834)^{21}$, es uno de los elementos básicos en torno a los que se fragua este texto, uno de los máximos exponentes del Romanticismo español.

Desde el drama barroco, pasando por los grandes poemas románticos, se llega así, en la segunda mitad del siglo XIX, a la novela como género literario por excelencia. Las ilusiones del doctor Faustino se publicó entre 1874 y 1875 en la Revista de España. En la Postdata que el autor añadió a la segunda edición de la obra, Valera afirma lo siguiente:

[...] el doctor Faustino es un personaje que tiene algo de simbólico o de alegórico. Representa, como hombre, a toda la generación mía contemporánea: es un doctor Fausto en pequeño, sin magia ya, sin diablo y sin poderes sobrenaturales que le den auxilio. Es un compuesto de los vicios, ambiciones, ensueños, escepticismo, descreimiento, concupiscencias, etc., que afligen o afligieron a la juventud de mi tiempo. [...] En su alma asisten la vana filosofía, la ambición política y la manía aristocrática. [...] D. Faustino, dado mi plan, no podía ser sino como es. Fausto es más grande; pero también es más egoísta, más pervertido y más pecaminoso. (451-452)

Que esta novela contenga alusiones directas al personaje goethiano y sea, en cierto modo, una rescritura del drama alemán en clave realista no debe resultar extraño, puesto que Valera fue durante toda su vida un gran admirador del pensamiento de Goethe, de entre cuyas obras sintió siempre una predilección especial por Fausto $^{22}$.Ya el propio título de la novela adelanta lo que será el argumento y lo relaciona de manera directa con el tema fáustico: por

${ }^{21}$ El joven caballero Sancho Saldaña, enamorado de la bella Leonor, se retira a su castillo de Cuéllar, tras fracasar las intrigas de su padre. Allí la pasión le unirá a la bella Zoraida, una cautiva mora. Tras ser despechada, Zoraida, con ayuda de artes de brujería, conseguirá que Sancho cometa las mayores atrocidades.

${ }^{22}$ En 1845, durante sus años de estudiante en Granada, llegó a escribir una Fábula de Euforión, tomada de la segunda parte del Fausto, la cual figura actualmente entre sus poesías. También escribió el ensayo titulado «Algo sobre las rarezas de Fausto», tras haber acudido a una representación de la obra en Viena en 1896. Asimismo tradujo algunos fragmentos y redactó un prólogo para la traducción del drama que llevó a cabo Roberto English en 1878 . 
un lado el nombre del protagonista, un doctor, Faustino, que no Fausto, diminutivo, pues, del personaje de Goethe; por otro, y ocupando incluso un lugar más destacado que el propio nombre, aquello que constituye su gran error vital, las ilusiones. Así, la forma diminutiva que emplea Valera apunta ya de entrada una gran diferencia entre ambos protagonistas, pues Faustino no llegará a tener nunca la grandeza trágica del personaje goethiano.

La obra aparece, por tanto, concebida en términos completamente antagónicos respecto del texto del autor alemán, pues lo que el autor pretende es «hacer una pintura de las costumbres y pasiones de nuestra época; una representación fiel y artística de la vida humana.» (448) No es de extrañar que Faustino presente características muy similares a las del protagonista de $E l$ estudiante de Salamanca y que su fracaso en la vida esté dominado precisamente por esa pérdida de las ilusiones, y es que Faustino, siguiendo la moda, es, ante todo, un gran romántico, y en ese sentido se ve a sí mismo como un genio, pero un genio incapaz de creer en la magia ni en la ciencia como recursos para poder alcanzar amor, fama, placeres y fortuna. Sus ilusiones pretenden hacer coincidir fantasía y realidad, de ahí que viva siempre esperando ver cómo sus imaginaciones cuajan en realidades, algo que, evidentemente, nunca llegará a suceder.

A diferencia del Fausto de Goethe, Faustino permanece siempre prisionero de su mundo ilusorio y anárquico pleno de fantasías delirantes, orientadas hacia un horizonte de expectativas quimérico e inalterable. Faustino entra en constante conflicto con su naturaleza, pero sobre todo entra en conflicto con la coyuntura histórica y social del momento en que vive, en el que las estructuras sociales han dado paso a una visión desencantada del mundo, consecuencia de las exigencias modernas de un nuevo modelo de sociedad en el que se valora la posición económica por encima de la clase social ${ }^{23}$. Esta transformación se plasma en la obra también en la reducción materialista y racionalista a la que Valera somete el motivo principal del pacto, pero que pretende ni más ni menos que los mismos objetivos definidos ya en los dramas barrocos y en los poemas románticos:

Si hubiese creído en la posibilidad de pactar con el diablo, hubiérale dado cuanto hay que dar al diablo a trueque de un ferviente amor, de un punto fijo y radiante, que fuese estrella polar en el mar impetuoso de su vida, y al mismo tiempo centro poderosísimo de atracción que le agitase y encaminase. (281)

Faustino siente la inquietud fáustica, pero no cree en la posibilidad de establecer un pacto con ningún ser superior; su único anhelo es conseguir un amor inalcanzable, de ahí que en la novela el pacto que tiene lugar sea exclusivamente un pacto amoroso entre él y María, la mujer misteriosa y con

${ }^{23}$ Véase al respecto mi artículo «Fausto vs. Faustino... y vs. Faustulus. Acerca de la desintegración del mito fáustico en las novelas de Juan Valera (1874/75) y Friedrich Spielhagen (1898)», mencionado en la bibliografía. 
un halo de sobrenatural, puesto que en una época marcada por el pensamiento positivista y racionalista, el diablo no puede desempeñar ya ningún papel: el hombre ha perdido su fe en él.

Que Valera sentía verdadera admiración, al tiempo que también atracción, por la trama fáustica lo demuestra el hecho de que en su última novela, Morsamor (1899), el autor volvió a tratar una vez más este tema. Recurriendo al género de la novela histórica, Morsamor narra la historia de un fraile del siglo XVI, Fray Miguel de Zuheiros, que, cansado de su vida monacal, desea volver a vivir una juventud, según él, desperdiciada, pues de muy joven había entrado en el convento porque, al igual que a Faustino y a otros personajes del siglo, «la desilusión, la esperanza perdida, le trajo a la vida monástica.» (25). Y así, «no acertaba a descubrir nuevos ideales, nuevos objetos, término y meta de la ambición humana. [...] Hízose, pues, religioso, por no saber qué hacerse. Y ya se comprende que esta manera de hacerse religioso de poco o nada podía valerle así en la tierra como en el cielo.» (25-26) Al igual que hiciera Faustino, Fray Miguel se plantea recurrir a fuerzas sobrenaturales:

¿Era él tan vil y tan indigno que no lograse ponerse en comunicación con seres inteligentes que no formen parte del linaje humano? El universo está lleno de tales seres. ¿Por qué eran tan groseros sus sentidos que no los percibían? ¿No podría él evocarlos, formar pacto y alianza con ellos y adquirir virtudes, poder y fuerzas superiores a cuanto posee la generalidad de los mortales de su misma especie? [...] Sin duda no me ha faltado ni la atención ni el propósito, ni el valor de darme al diablo; pero no me quiere y me desdeña. (55)

Sumido en estos pensamientos recurre, pues, a la magia de otro monje, el padre Ambrosio de Utrera, del que «se suponía que de magia natural, astrología y alquimia sabía cuanto podía saberse en su tiempo, y que él además, a fuerza de estudios, meditaciones y experiencias, había descubierto grandes misterios y secretas propiedades y leyes de las cosas creadas» (31), y, tras haber recobrado la juventud perdida, con su nuevo nombre de Morsamor, inicia un viaje en compañía de un acólito, Tiburcio, hacia tierras de Oriente, donde tendrá visiones y vivencias espectaculares, así como también una experiencia amorosa. No obstante, no puede afirmarse que Morsamor posea las características propias de Fausto, pues, al igual que al resto de los personajes españoles, no le mueve tampoco una sed de conocimiento insaciable, sino tan sólo el deseo de vivir experiencias no vividas. La obra concluye asimismo con el desengaño del protagonista, que regresa al convento en un estado de mísera salud física, pero mejorado espiritualmente tras haber encontrado las respuestas que buscaba antes de haber decidido revivir su juventud.

No es posible concluir este recorrido por las rescrituras de la trama fáustica en la literatura española sin mencionar el poema en ocho cantos, compuesto en versos endecasílabos y heptasílabos, de Ramón de Campoamor: El licenciado Torralba (1888). Para la composición de su obra Campoamor par- 
te de la leyenda del doctor Eugenio Torralba, quien, a principios del siglo XVI, alcanzó gran popularidad en toda España, no ya por sus habilidades médicas, sino por contar con la amistad de un misterioso personaje, Zequiel, del que se decía que no pertenecía a este mundo ${ }^{24}$. Se hizo famoso por haber descrito el Sacco di Roma (6 de mayo de 1527) mucho antes de que llegaran a España las primeras noticias de él, afirmando haberlo presenciado en persona gracias a un supuesto viaje aéreo desde Valladolid a Roma, que había realizado guiado por una especie de nube de fuego, y en el que no había tardado más de media hora. Poco después fue detenido por la Santa Inquisición y torturado hasta la muerte ${ }^{25}$.

El hecho de que la figura de Torralba no haya aparecido en demasiadas obras literarias a lo largo de los siglos ${ }^{26}$ se debe seguramente a que, en épocas inmediatamente posteriores a la suya, la leyenda de Fausto, sobradamen-

${ }^{24}$ El propio Cervantes menciona al licenciado Torralba en el Quijote, al hilo de la famosa aventura de Clavileño, lo cual puede dar una idea de lo apuntado respecto de la fama de este curioso personaje: «-Que me maten si no estamos ya en el lugar del fuego, o bien cerca; porque una gran parte de mi barba se me ha chamuscado, y estoy, señor, por descubrirme y ver en qué parte estamos.

-No hagas tal - respondió Don Quijote-, y acuérdate del verdadero cuento del licenciado Torralba, a quien llevaron los diablos en volandas por el aire, caballero en una caña, cerrados los ojos, y en doce horas llegó a Roma, y se apeó en Torre de Nona, que es una calle de la ciudad, y vio todo el fracaso y asalto y muerte de Borbón, y por la mañana ya estaba de vuelta en Madrid, donde dio cuenta de todo lo que había visto; el cual asimismo dijo que cuando iba por el aire le mandó el diablo que abriese los ojos y los abrió, y se vio tan cerca, a su parecer, del cuerpo de la luna, que la pudiera asir con la mano, y que no osó mirar a la tierra por no desvanecerse.» Cervantes, Miguel de, Don Quijote de La Mancha II (353-354). Don Quijote veía estos vuelos por los aires como un hecho dignificador de la figura del caballero andante: «Muchas y muy graves historias he yo leído de caballeros andantes; pero jamás he leído, ni visto, ni oído, que a los caballeros encantados los lleven desta manera y con el espacio que prometen estos perezosos y tardíos animales; porque siempre los suelen llevar por los aires, con estraña ligereza, encerrados en alguna parda y escura nube, o en algún carro de fuego, o ya sobre algún hipogrifo o otra bestia semejante; $[. .$.$] .$ Cervantes, Miguel de, Don Quijote de La Mancha I (594).

${ }^{25}$ Así lo describe Menéndez Pelayo en su Historia de los heterodoxos españoles, en el capítulo titulado «Principales procesos de hechicería»: «Salieron de Valladolid en punto de las once, y cuando estaban a orillas del Pisuerga, Zequiel hizo montar a nuestro médico en un palo muy recio y ñudoso, le encargó que cerrase los ojos y que no tuviese miedo, le envolvió en una niebla oscurísima, y después de una caminata fatigosa, en que el doctor, más muerto que vivo, unas veces creyó que se ahogaba, y otras que se quemaba, remanecieron en Torre de Nona, y vieron la muerte de Borbón y todos los horrores del saco. A las dos o tres horas estaban de vuelta en Valladolid, donde Torralba, ya rematadamente loco, empezó a contar todo lo que había visto.» (373) Aunque se desconocen la fecha y el lugar de nacimiento, la práctica totalidad de los datos relativos a su biografía están recogidos en el manuscrito del proceso inquisitorial que tuvo lugar en Cuenca en 1531, y que se conserva en la Biblioteca Real de El Escorial.

${ }^{26}$ La figura del doctor Torralba ha sido objeto de varias rescrituras en la segunda mitad del siglo XX, entre las que destacan la obra de teatro de Domingo Miras, El doctor Torralba (1980-1982) y la novela de Eduardo Gil Bera, Torralba (2002). 
te conocida por los estudiantes de Salamanca, así como las leyendas hagiográficas de la tradición medieval, se avenían mucho mejor con las necesidades literarias del momento. El trágico final del Dr. Fausto, así como la redención de los santos y mártires que protagonizaban las leyendas, resultaban mucho más ilustrativos para la moral barroca que la historia del estrambótico licenciado hispano, cuyo final no se diferenciaba en mucho del de otros tantos perseguidos y condenados por el Santo Oficio. En cualquier caso, la obra que lo ha inmortalizado, y aunque Campoamor la escribiera en fecha bastante posterior, debería situarse en paralelo al Fausto de Goethe, al Manfred de Lord Byron, al Don Juan de Zorrilla o a El diablo mundo de Espronceda, pues, como ellas, constituye una indagación en el sentido de la existencia, un lento e inexorable viaje a través del cambiante y contradictorio panorama de la peripecia de una vida singular ${ }^{27}$. Y es precisamente en este contexto donde ha de ser analizado, no como una rareza aislada, como es entendida la práctica totalidad de la obra de este autor asturiano, sino como un fruto tardío y peculiar del movimiento romántico, tanto por lo que a la forma como a la construcción de una obra en torno a tan singular individuo se refiere. Y es que convertir a tal personaje en protagonista de un poema simbólico a finales del siglo XIX no era tarea fácil, pues, seguramente, la historia de Torralba no ofrecía para un lector de ese momento otro interés que el puramente pintoresco o documental. Pero el autor deja bien claro que lo que le interesa no es simplemente narrar la biografía de un personaje histórico tachado de excéntrico, sino transformarla en algo significativo, en una experiencia metafísica, esto es, en una indagación sobre temas de más alto interés. Para ello, se aleja de lo meramente anecdótico, reduce a un mínimo lo episódico y se centra en determinadas aventuras, algunas probablemente inventadas, lo cual le permite llevar a cabo un análisis del alma del nigromante y, a través del mismo, plantear el sentido de la existencia humana. Esto es: Campoamor invierte la estimación del personaje y, rebajando valoraciones ya consagradas ${ }^{28}$, hace que un individuo condenado a la marginación social por sus actividades, sea digno de estimación y respeto, porque a través de las experiencias de Torralba, el autor puede someter a examen la que resulta ser la cuestión fundamental del ser humano: su naturaleza contradictoria, que lo conduce sin cesar a una

${ }^{27}$ Sin embargo, la obra de Campoamor ha sido, y continúa siendo aún hoy en día, un enigma para la crítica, tal como aventuró hace ya mucho tiempo Jaime Dubón: «Los críticos que han intentado penetrar en el fondo de ese temperamento literario no han acertado con la clave capaz de explicar el misterio y algunos, en el colmo del enojo, han llegado a tratarle mal.» (24)

${ }^{28}$ Entre ellas se encuentran la de llamar tonto a Platón («¿Cómo habrá un hombre racional, que crea / que en la vida no existen más placeres / que aquellos que son hijos de una idea? / ¡Oh, divino Platón! ¡qué imbécil eres!», 109) o la de la obviedad de las verdades científicas («[Torralba] acabó por odiar la poesía, / amó las ciencias y olvidó las artes, / llegando así á saber que en todas partes / calienta el fuego y que la nieve enfría.», 90). 
busca inútil de algo que le procure felicidad y paz interior, puesto que el licenciado español, tal como le ocurriera al doctor alemán, no puede más que constatar una y otra vez la insuficiencia de todos los principios:

Torralba es de esos hombres atrevidos,
que si no se las dan, toman las cosas,
que después que robó varias esposas,
las volvió á regalar á sus maridos.
Este hombre sin ventura
se educó en seminario, y salió ateo,
y, aunque algún día, creo
que al salir de una orgía, se hará cura,
deduciendo aquella alma fementida
que la conciencia es una gran quimera,
la echó al mar en seguida,
logrando aligerar de esta manera
la carga de la nave de la vida.
Buscando en sus acciones,
sin reparar en medios, la fortuna,
variaban en moral sus opiniones,
y no habiendo más que una,
como todo el que estudia religiones
se quedó al fin del curso sin ninguna. (68

Torralba vive también la experiencia amorosa, pero aquí, el protagonista, desencantado del puro idealismo que representa el alma de Catalina, su amada, busca la felicidad en la materia, para lo que crea una mujer de barro con ayuda del maligno. Y así, fundiendo leyenda, historia, teología y filosofía, Campoamor da vida a un personaje de características muy similares a las del Fausto de Goethe, a través del cual pone de manifiesto los temas que le ocuparon durante la práctica totalidad de su vida y que configuraron la mayoría de sus obras poéticas: la poca confianza que le inspira el género humano, dominado por sus impulsos menos elevados, así como por la duda permanente que le suscitan las ciencias o cualquier clase de doctrina.

Lo novedoso aquí, y lo que hace que esta obra se diferencie de las muchas otras en las que se desarrolla la trama del erudito decepcionado que se deja llevar de la mano de un ser infernal a fin de encontrar en la vida algo que le saque de ese estado, es el hecho de que el autor aprovecha la situación del personaje y sus viajes por el mundo para ejercer una dura crítica social solapada bajo una fina capa de burla y socarronería, difícil de llevar a cabo con igual libertad desde otras perspectivas ${ }^{29}$, y así, Campoamor hace que Torralba, un personaje real, desde su escepticismo absoluto, pero con la ironía que lo caracteriza como sabio desengañado, someta a juicio los valores de su tiempo, del siglo XIX, igual que hiciera ya Espronceda en El diablo

\footnotetext{
${ }^{29}$ Véase al respecto mi artículo «De visiones y pactos: elementos fáusticos en El diablo cojuelo de Luis Vélez de Guevara y El licenciado Torralba de Ramón de Campoamor».
} 
mundo ${ }^{30}$. Pero a diferencia de éste, Campoamor no se deja arrastrar por sus sentimientos, sino que su faceta irónica le hace tener una visión mucho más amplia de su época, al tiempo que pone el necesario espacio entre él y su creación: mientras Espronceda cree que hay una solución posible al desengaño, Campoamor, como es característico de su ironía y escribiendo además el poema a finales de siglo, destruye toda esperanza de ello, puesto que su personaje, al igual que otros muchos anteriores a él, ha perdido por completo las ilusiones ${ }^{31}$.

En las postrimerías del siglo XIX, en 1897, Clarín rescribió en un breve drama titulado Nuevo contrato dos escenas que transcurren en el gabinete de estudio del doctor Fausto, uno de los momentos clave del drama goetheano. Se trata de la plasmación literaria del autor de su «batalla artística entre positivismo y espiritualismo, entre lo físico y lo metafísico» ${ }^{32}$, puesto que si en el modelo de Goethe se impone la búsqueda del conocimiento absoluto, del saber, en la versión de Clarín la ciencia acaba venciendo a los sentimientos: el ser que resulta del pacto es un ser racional, desprovisto de sentimientos, que ha de renunciar a sus sentimientos a favor del saber empírico, positivista. El dilema que se plantea en el texto de Clarín afecta a la misma esencia del hombre, puesto que Fausto no es arrastrado aquí por una fuerza externa de carácter maligno, sino que consiente en cerrar el trato en pleno uso de sus facultades y a sabiendas del alcance que éste tendrá posteriormente: si Fausto renuncia al esfuerzo sin descanso, caerá sin más en el abismo de la sensualidad y pasará a ser propiedad de Mefistófeles. Y aun a sabiendas de ello, Fausto apuesta, plenamente convencido de que será capaz de resistir a cualquier tentación de no hacer nada. Curiosamente, en esta nueva visión española del mito fáustico la ciencia vence a los sentimientos, y éstos son precisamente el precio que el protagonista ha de pagar por lograr el saber empírico ${ }^{33}$, positivista, del que, no obstante, el autor se mofa descaradamente en la obra.

30 «Mas si Espronceda se propone enseñarnos el mundo físico y moral, para probarnos que la inmortalidad de la materia es el hastío y la condenación sobre la tierra, juzgamos que su héroe, al retroceder en la carrera de la vida, debe hacerlo por completo, volviéndole la virginidad al alma, la inexperiencia al juicio, y dándole unas sensaciones no gastadas.» ROS DE OLANO, Antonio, «Prólogo», en: ESPRONCEDA, José de, El estudiante de Salamanca. El diablo mundo. (167)

${ }^{31}$ El único anhelo de personajes de similares características en esta época de fin de siglo no es otro que conseguir un amor sin par. Así, a diferencia del Fausto goethiano, permanecen siempre prisioneros de su mundo ilusorio y anárquico, pleno de fantasías delirantes, que les hace entrar en constante conflicto con la coyuntura histórica y social del momento en que viven, de ahí que su desencanto ante las tentaciones mundanas que tratan de superar los conduzca a cuestiones de mayor calado intelectual. Véase en este sentido mi estudio, mencionado anteriormente, «Fausto vs. Faustino... y vs. Faustulus. Acerca de la desintegración del mito fáustico en las novelas de Juan Valera (1874/75) y Friedrich Spielhagen (1898)».

${ }^{32}$ BALZER, Berit (206).

33 «Por arte del diablo, mía, tendrás en la cabeza la ciencia y en el corazón el sentir; si prefieres gozar, amar, tu cerebro irá perdiendo vigor, y pasará toda la vida al corazón». ALAS, Clarín, Leopoldo (27). 
Llegados a este punto, y a modo de conclusión de este recorrido por las rescrituras de la trama fáustica en el ámbito español, puede afirmarse lo siguiente: el valor moralizante que dominó la literatura española durante toda la Edad Media, el Renacimiento y el Siglo de Oro definió las letras hispanas durante siglos, con lo que los episodios de pactos diabólicos se convirtieron desde muy pronto en una fuente muy fecunda de inspiración para los más diversos autores. Por otro lado, la profunda vinculación cultural entre la sociedad española y la religión católica, que ha llegado hasta bien entrado el siglo XX, hizo que se desarrollara una literatura de intención moral que buscaba temas atractivos para los lectores o espectadores. De este modo, las historias de pactos con el diablo que se popularizaron en España a lo largo de diferentes periodos de la historia de la literatura no se centran en el conflicto interno del personaje, como ocurre en la literatura alemana, sino que los móviles que llevan aquí a los diferentes protagonistas a pactar con el diablo son mucho más mundanos y concretos (la consecución del deseo carnal o del amor de una mujer $)^{34}$ y no un afán de conocimiento desmedido. Además, la acción divina tiene en las obras españolas un papel fundamental que induce al pecador al arrepentimiento y que no se pone de manifiesto de una manera tan explícita en los muchos textos que, inspirados en la figura del nigromante alemán, se han escrito en otras latitudes.

\section{REFERENCIAS BIBLIOGRÁFICAS}

ALAS, Clarín, Leopoldo. «Nuevo contrato». En: Richmond, Carolyn (ed.). Obras completas. Oviedo: Nobel, 2006, vol. 3, pp. 951-955.

ATKINS Stuart. «Goethe, Calderón and Faust: Der Tragödie zweiter Teil». Germanic Review, 1953, XXVIII, pp. 83-98.

ARCIPRESTE DE HITA. Libro de Buen Amor. Blecua, Alberto (ed.). Madrid: Cátedra, 1992.

BALLESTEROS BARAHONA, Pedro. Calderóns erste Fassung von 'El mágico prodigioso' und das Doctor-Faustus-Spiel der englischen Komödianten. Berlín, Tesis doctoral, 1972.

BALZER, Berit. «Nuevo Contrato de Leopoldo Alas, 'Clarín': un nuevo punto de partida para Fausto en la literatura española», En: Gimber, Arno e Isabel Hernández (ed.). El Fausto en España: interpretación y recepción. Madrid: Editorial Complutense, 2009, pp. 201-211.

BIETOLINI, Incola. «Faust in miniatura. Dal Faust di Goethe al romanzo Las ilusiones del doctor Faustino di Valera». Neohelicon, 30, 2003, pp. 209-225.

${ }^{34}$ Así lo describe también Francisco J. Flores: «La idea de establecer un pacto con el diablo ha tentado a muchos españoles de todas las épocas, con resultados más o menos pintorescos. El fruto perseguido es siempre el mismo: el deseo de posesión de alguna mujer, de dinero, de un cargo sobresaliente... [...] un tal Miguel Vargas, de dieciséis años, que en los días de 1572 en Madrid, se confesó autor de haber hecho pacto con el diablo para hacerse invisible y así obtener el amor de una señora de la que andaba apasionadamente enamorado. El muchacho invocó a los demonios, dio al demonio en señal una uña, blasfemó, cometió sacrilegios con imágenes sagradas, pero no pudo salvar la frontera impuesta por la materia.»(67-68). 
BLASCO, F.J. et al. (eds.). La comedia de magia y de santos. Madrid: Júcar, 1992.

CAMPAL FERNÁNDEZ, José Luis. «Notas sobre El licenciado Torralba (1888) de Ramón de Campoamor». Letras Peninsulares, 2004-2005, 17/2-3, pp. 381-386.

CAMPOAMOR, Ramón de. El Licenciado Torralba. Barcelona: López, [s.d.].

CALDERÓN DE LA BARCA, Pedro. El mágico prodigioso. Madrid: Cátedra, 1996.

CASTAÑEDA, James A. «El esclavo del demonio y Caer para levantar: reflejo de dos ciclos». Studia Hispanica in Honorem R. Lapesa. Madrid: Gredos, 1974, vol. II, pp. 181188.

CERVANTES, Miguel de. Don Quijote de La Mancha. 2 vols. Rico, Francisco (ed.). Barcelona: Círculo de Lectores, 1989.

DON JUAN MANUEL, El conde Lucanor. Blecua, José Manuel (ed.). Madrid: Castalia, 1969.

DUBÓN, Jaime. «Estudio preliminar». En Obras poéticas completas. Ramón de Campoamor. Madrid: Aguilar, 1929.

ESPRONCEDA, José de. El estudiante de Salamanca. El diablo mundo. Marrast, Robert (ed.). Madrid: Castalia, 1993.

FERNÁNDEZ RODRÍGUEZ, Natalia. El pacto con el diablo en la comedia barroca. Oviedo: Universidad de Oviedo, 2007.

FLORES, Francisco J. El diablo en España. Madrid: Alianza, 1985.

GONZALO DE BERCEO. Milagros de Nuestra Señora. Baños Vallejo, Fernando (ed.). Madrid: Crítica, 1997.

GONZÁLEZ SERRANO, Urbano. «Goethe». En: Ensayos Críticos. Urbano González Serrano. Madrid: Imprenta de Luis Carrión, 1892.

HERNÁNDEZ, Isabel. «Fausto vs. Faustino... y vs. Faustulus. Acerca de la desintegración del mito fáustico en las novelas de Juan Valera (1874/75) y Friedrich Spielhagen (1898)». El Fausto en España: interpretación y recepción. En: Gimber, Arno e Isabel Hernández (ed.). Madrid: Editorial Complutense, 2009, pp. 181-199.

—. «De visiones y pactos: elementos fáusticos en El diablo cojuelo de Luis Vélez de Guevara y El licenciado Torralba de Ramón de Campoamor». Anuario Argentino de Germanística, 2009, IV, pp.191-206.

LITVAK, Lily. «Morsamor: un viaje de iniciación hacia la India». Hispanic Review, 1985, 53, pp. 181-199.

LORENZO, Emilio. «Goethe, visto por los españoles del siglo XIX». Cuadernos hispanoamericanos, 1957, 88, pp.53-72.

MENÉNDEZ PELAYO, Marcelino. Historia de los heterodoxos españoles. Madrid: CSIC, 1947, vol. IV.

MIRA DE AMESCUA, Antonio. El esclavo del demonio. Castañeda, James Agustín (ed.). Madrid: Cátedra, ${ }^{2} 1984$.

MONTESINOS, José F. Valera o la ficción libre. Madrid: Castalia, 1969.

MORENO HERNÁNDEZ, Carlos. «Valera, Faustino y el mal del siglo». Revista de Literatura, 1999, LXI/122, pp. 449-466.

MORETO, Agustín; MATOS FRAGOSO, Juan de; CÁNCER, Jerónimo de. Caer para levantar. Valencia: Universidad de Valencia, 2001.

NICAU CASTAÑO, Arlindo José. «A construção da imagem do Fausto, de Cipriano de Antioquia a Fernando Pessoa». Revista de lenguas y literaturas latinoamericanas, 2002, 1, pp. 1-17.

PAGEARD, Robert. Goethe en España. Madrid: CSIC, 1958.

PARRA MEMBRIVES, Eva. Roswitha von Gandersheim. Madrid: Del Orto, 2001.

RUFFINATTO, Aldo. «El santo, el diablo y la «sutil nigromancia» (Notas sobre el Fausto español del Siglo de Oro)». En: Blasco, F.J. et al. (eds.). La comedia de magia y de santos. Madrid: Júcar, 1992. 
RUKSER, Udo. Goethe in der hispanischen Welt. Stuttgart: Metzler, 1958.

SIGUAN, Marisa; JANÉ, Jordi. «El Fausto en España». Libros, 1983, 21, pp. 12-16.

VALERA, Juan. Las ilusiones del doctor Faustino. Madrid: Castalia, 1995.

-. Morsamor. Madrid: Celeste, 2000.

ZAYAS Y SOTOMAYOR, María de. Novelas amorosas y ejemplares. Olivares, Julián (ed.). Madrid: Cátedra, 2000.

ZEITLIN, M.A. «El condenado por desconfiado y El esclavo del demonio». Modern Language Forum, 1945, XXX/1-2, pp.1-5.

Fecha de recepción: 6 de agosto de 2009

Fecha de aceptación: 1 de febrero de 2010 